\title{
Meta-Analysis of Gold Price and Major ASEAN Currency (Malaysian Ringgit, Singapore Dollar, Thai Baht) Against US Dollar
}

\author{
Michael Tinggi, Shaharudin Jakpar, Amy Chin Ee Ling, Akmal Hisham and \\ Daw Tin Hla \\ Faculty of Economics and Business, Universiti Malaysia Sarawak (UNIMAS)
}

\begin{abstract}
With the exit of Bretton Woods System and the Gold Standard, the floating exchange rate, was adopted by most country in the ASEAN region. Floating exchange rate has been a major debacle issue for the volatility of world gold price in relation to national currency value including that of the ASEAN region. The motivation behind this empirical study is to examine the relationship between gold price and exchange rate of ASEAN major currencies such as Malaysian Ringgit (MYR/USD), Singapore Dollar (SGD/USD), and Thai Bath (THB/USB) against the US dollar. Gold price is primarily dominated in US dollar, and any variation in US dollar may influence the value of other currencies. The monthly meta-analysis involves the study of a span of 30-year data, effective from 1981 to 2010. While the findings report no short term relationship, a Johansen Co-integration test finds evidence of a long term relationship between gold price vis-a-vis the exchange rate of major ASEAN currencies, such as MYR/USD, SGD/USD and THB/USD. Further evidence from Ordinary Least Square analysis shows that gold price has a positive relationship with MYR/USD but reports perverse relationship against SGD/USD and THB/USD.
\end{abstract}

Keywords: ASEAN currency, gold price, meta-analysis, US dollar

\section{INTRODUCTION}

The medium of exchange over the centuries among many countries has seen many magnitudes of changes and evolutions. No single currency or medium has been considered stable over times. The early stage of trading involves barter trading, which developed into using commodities as medium of exchange beside gold. Oil discoveries and its significance compel researcher to make an analysis on the relationship of gold, oil prices, US dollar and the stock market (Azar, 2015). Studies were enhanced on exploring relativity among gold, oil and foreign currencies and how much would one unit affects the other (Malliaris and Malliaris, 2013; Zagaglia and Marzo, 2013)). Gold price adopted as a medium of exchange, has been a stabilizing driver of the exchange rate for centuries (Broz and Frieden, 2006) and has been considered as a substitute for portfolio risk reduction (Mansor, 2011). On many occasions, gold can be used as an investment hedge against the US dollar (Joy, 2011). The post 2nd world war saw the abandonment of the Gold Standard due to socio-economic instability caused by the war. A new international monetary system called the Bretton Woods Agreement of 1944 was established to maintain a fixed but adjustable exchange rate system. However, the Bretton Woods regime was short-lived, when the President of the United States, Richard Nixon declared an end to the use of gold standard in 1971, due to the insufficient supply of US gold stock to support the value of the pegged rate of US \$35 per ounce of gold. 
The year 1972 saw the adoption of the Smithsonian Agreement, which applied the fixed exchange rate system with "currency realignment" but it was only for a temporary measure, before a new floating exchange rate regime came into force in 1973. It is a self-correcting rate system, whereby the currency is determined by private market through the forces of supply and demand. Any differences in the supply and demand will be automatically corrected in the market.

Over a period of time, the value of dollar had been relatively stable especially the years preceding 1971. The subsequent period reported a sharp drop in the value of dollar, as the US dollar was no longer pegged or convertible to gold price. The value of US dollar began to fluctuate based on the demand and supply of US dollar in the private and open market. This is demonstrated in Table 1.

Figure 1: Movement of the value of US currency against the gold over a period of 50 years.

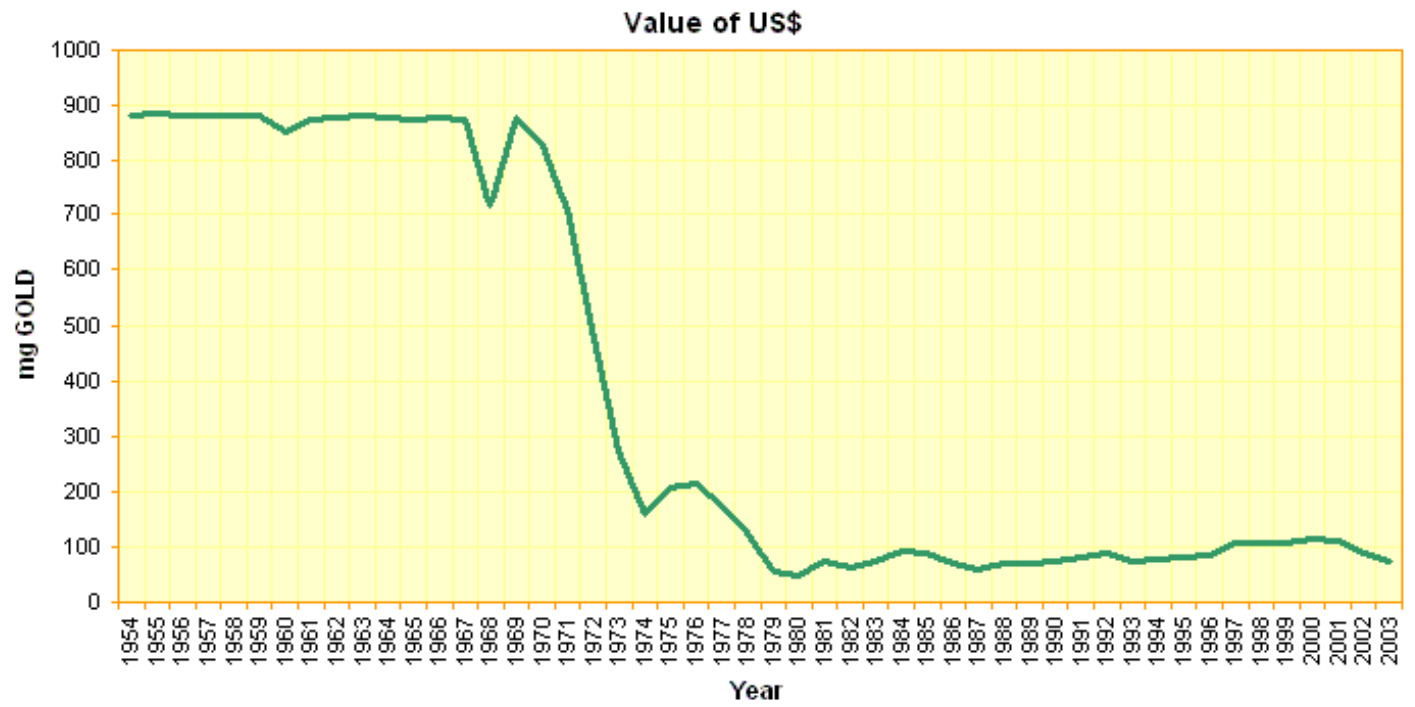

Source: Morris, J.H. (2008)

Over the years we have observed the movement of currencies, which may react either positively or negatively to the price of gold and the US dollar. When gold was pegged to UD dollar, a lot of currencies especially in the ASEAN region will see the value of their currencies either rise or fall, in relation to the value of US dollar against the gold price. Another area of interest is the direct influence of gold price on the value of currencies especially in the ASEAN region which may either move up or down in reaction to a rise or fall in gold price. An early research by Faugere and Van Erlach (2005), find that there is an inverse relationship between the gold price and the US dollar, which is not consistent with the reported strong value of the Australian dollar when the gold price goes up.

Thus, this study is to examine whether there is a positive or negative relationship between gold price and currencies of the ASEAN region. Besides, there is no evidence of early research to determine the short-term and long-term relationship between gold price and exchange rate of US Dollar against ASEAN currency such as MYR, SGD and THB. Thus, this research is carried out in order to determine the relationship between gold price and exchange rate in developed and developing countries for both short-term and long-term periods. 
With rising or decreasing value of US dollar and gold, it may provide investors with the alternative form of investment. When the currencies strengthen, the investors will choose to invest in the currencies rather than gold or vice versa. Gold which serves as a portfolio diversification, provide information to investors on the correlation and changes among gold price and the exchange rates, thus they can exploit the potential benefit through the control of portfolio's exposure and cushioning the impact of unnecessary loss and risk.

\section{The Required Yield Theory}

The valuation of gold price is motivated by earlier study of Faugere and Van Erlach, 2005, in its Required Yield Theory. It is an asset pricing theory that explains the valuation of financial assets via investors' general requirement to earn a minimum expected after-tax real return equal to longterm GDP/ capita growth. As a store of value, the yield of gold must have a negative relationship with the yield of other financial asset class. Thus gold serve as a hedge against the devaluation of other financial asset class such the country currency. Capie, Mills \& Wood (2005) finds that gold serve as a hedge against US Dollar; while Ghosh, Macmillan \& Wright (2002) reports that gold serve as a hedge against long-term inflation. The gold helps to hedge against US dollar in two ways, which is either internally or externally. Base on the internal hedging, the gold would be hedged against the changes in the domestic purchasing power of dollar. The external hedging would gold against the changes in the international purchasing power of dollar. In a perfect internal hedging market, the dollar price will increase at the same rate as the U.S. price index. However, in a perfect external hedging market, the dollar price will increase when the number of unit of foreign currency per dollar decrease at the same rate and at the same time.

\section{The Relationship of Malaysian Ringgit (MYR), Singapore Dollar (SGD) and Thai Baht (THB) with US Dollar (USD)}

\section{The Relationship of MYR and USD}

The former Malaysia's currency was linked to the Pound Sterling known as the old-Sterlinglinked Malaysian/ Straits Dollar. In June 1967, the unit of Malaysian Dollar (M\$) was established and replaced the old-Sterling-linked Malaysian/ Straits Dollar. The Central Bank of Malaysia, Bank Negara Malaysia (BNM), has taken control of the currency exchange of the country. Besides, BNM has also delegate the authority to all authorized banks in the county to adopt the "effective rate" which is a floating but controlled exchange rate regime. BNM is only involved in maintaining stable market condition and to ensure that the fluctuation of Malaysian currency in term of foreign currency is not excessive. In 1975, the floating and the controlled exchange rate regime ceased. In the same year, the external value of Malaysia's currency was measured based on its relationship with a weighted basket of currencies of Malaysia major trading partners M\$ was replaced with Malaysian Ringgit (MYR). The exchange rate regime remains the same till the Asian Financial Crisis 1997/1998, where the RM was no longer measured by the demand and supply of currencies in the foreign exchange market. Thereafter, Malaysia has adopted a fixed exchange rate system in which RM is pegged to the USD at a rate of RM 3.80 per dollar.

In 2005, Malaysia returned to the floating exchange rate regime. This is because the fixed exchange rate did not seem to bring effective result in eliminating the volatility of the local currency. Thus, it merely shifts the volatility to the domestic price such as asset prices and inflation. By adopting the floating exchange rate regime, it gives the flexibility for Malaysia to adjust to the development of international economic and financial development. 


\section{The Relationship of SGD and USD}

In 1967, the Singapore Dollar (SGD) was established. Singapore has adopted a fixed exchange rate. Formerly, it was linked to Pound Sterling and subsequently was linked to USD. During the period of 1973-1985, the value of SGD is determined by fixed and undisclosed trade-weighted basket of currencies (exchange rate regime of a basket system). In 1985, Singapore adopted a floating exchange rate system. The foreign exchange rate of Singapore is monitored and controlled by the Monetary Authority of Singapore (MAS), against the basket of other major currencies. During the Asian Crisis, the SGD is allowed to fluctuate within an undisclosed basket of major trading partners' currencies.

After the Asian Financial Crisis, most of the ASEAN countries have transferred from pegged exchange rate system to a floating exchange rate system. This includes Singapore, however, there were some structural changes in the basket weights of SGD.

\section{The Relationship of THB and USD}

The currency of Thailand is Thai Baht (THB). The Bank of Thailand (BOT) controls the currency exchange of the country. Before 1963, Thailand has adopted a floating exchange rate regime. Nevertheless, Thailand ended the floating exchange rate regime in 1963, and subsequently THB was linked to the USD at a rate of B20.80 per USD. In July 1973, the BOT adopted $4.5 \%$ of fluctuation range while increasing the value of Baht to B20.00 per USD. This was to prevent the continuous reduction of gold reserves during the adoption of fixed exchange rate system.

In March 1978, the pegged exchange rate system to USD was removed and the Thai Baht was pegged against a weighted basket currency of Thailand's major trading partners. The Effective Rate was established and the external value of THB was measured based on the basis of a weighted basket of currencies of Thailand's major trading partners.

With effect from 2 July 1997, Thailand has adopted a floating exchange rate regime. Thereafter, the value of THB was determined by its demand and supply in the foreign exchange market. The BOT will only intervene to avoid excessive volatilities with the objective of trying to achieve economy policy target. During the Asian Financial Crisis, the value of the THB decreased and their market values also went down until half of its value during the pre-crisis level. However, the THB has stabilized at the end of January 1998.

\section{LITERATURE REVIEW}

A study by Sjaastad (2008) shows evidence, that a change in major currency exchange rate (dollar, euro and yen) affects the foreign currency price of gold. Han, Xu \& Wang (2008) find both long term relationship between Australian dollar against US dollar exchange rates and gold price covering period from 6 January 2002 to 10 February 2008. In the short term however there is no evidence of causality and short-term relationship between gold price and $€ / \$$ exchange rate and between gold price and interest rate (GÜNEŞ et al, 2009). In a study by Pukhuanthong and Roll (2011), the price of gold in a depreciating currency tends to rise and vice versa, and the findings seem to be consistent with the study by Beckmann, et al. (2015), that depreciation in exchange rate has negative effect on gold prices. In an earlier reverse study of foreign currency, on the casual relationship between variables, exchange rate seems to cause all other variables to change including gold (Jain and Ghosh, 2013) 
Gold is found to provide an alternative form of safe heaven. Marzo \& Zagaglia (2010) employ Generalized Autoregressive Conditional Heteroscedasticity (GARCH) model, and finds that the exogenous volatility shocks that has increased the market uncertainty tend to generate a stable gold price as oppose to the US Dollar. Capie, Mills \& Wood (2005) suggest that gold serves as a good hedge against the fluctuation of foreign exchange value of the dollar subject to non-influential effect from events and circumstances. Baur \& Lucey (2010) however contend that gold provides hedging and a safe haven for stocks in all market but it does not hedge well for bond market. Ghosh, Levin, Macmillan \& Wright (2002) report that the gold can be served as a long-term hedge against inflation and the gold price move align with the US price level. As Joy (2011) opines, gold also serve as an investment hedge against the US dollar. A study by Ghazali et al, 2015 finds no systematic relationship between gold serving as a short term hedge against inflation, while gold can be considered as an efficient alternative for portfolio reduction (Mansor, 2011). Figuerola-Ferretti \& Gonzalo (2010), present in a non linear price discovery equilibrium model that under a strong dollar and low volatility, gold and silver may not serve as a good hedge for the same types of risk. Wang, Wang \& Huang (2010) study also indicates that there is no cointegration and long-term relationship among the crude oil price, gold price, and exchange rates and US stock market index. This seems to be quite consistent with the recent study by Partalidou, et al (2016), that purchase of gold may negatively affect the US dollar through an inverse effect of low return from stock market. In an empirical examination by Blose (2005), changes in expected inflation towards the interest rate and gold price tend to indicate that the CPI only affects the interest rate but not the gold price.

\section{METHODOLOGY}

\section{Data Description}

The secondary data that are collected involves a time span of 30 years starting from 1981 to 2010 showing the effect of the floating exchange rate regime when the Bretton Woods System and Gold Standard ends in 1971. Hence, the relationship between gold price and the fluctuation of the exchange rate can be examined during the duration of the floating rate system. The data collected include monthly data of gold price (USD per ounce) and monthly exchange rate of USD-MYR, USD-SGD, and USD-THB covering period from Jan 1981 to December 2010. The monthly gold price data obtained from the World Gold Council website and the monthly currency exchange rates are obtained from Board of Governors of the Federal Reserve System website

\section{Unit Root Test}

The Unit Root Test is a statistical test that is used to examine whether the time series variables are stationary or non-stationary under the autoregressive model. The Augmented Dickey-Fuller (ADF) unit root test which was developed by Dickey and Fuller (1981) and applied in this study to test the stationary or non-stationary of the monthly data of gold price and currencies exchange.

$\Delta \gamma_{t}=\beta_{1}+\beta_{2} t+\beta_{3} t+\delta \gamma_{t-1}+\alpha_{1} \sum_{i=1}^{m} \alpha_{i} \Delta \gamma_{t-i}+\varepsilon_{\mathrm{t}}$

$\gamma_{t}=$ dependent variable such as gold price $(\log \mathrm{GP})$

$\Delta=$ first difference operator

$\beta_{1}, \beta_{2}, \beta_{3}, \delta, a_{1}, \ldots \ldots, a_{p}=$ a set of parameter to be estimated 
$\Delta \gamma_{t-1}=\left(\gamma_{t-1}-\gamma_{t-2}\right)$

$\varepsilon_{\mathrm{t}}=$ pure white noise error term

The null hypothesis $\left(\mathrm{H}_{0}\right)$ and alternative hypothesis $\left(\mathrm{H}_{1}\right)$ of ADF unit root test are as below:

\section{$\mathrm{H}_{0}: \delta=0$ (unitroot exist) \\ $\mathrm{H}_{1}: \delta \neq 0$ (unit root do not exist)}

The unit root test is carried out to test the stationary of time series data. If the value of $t$ statistic is greater than the critical value, the null hypothesis $\left(\mathrm{H}_{0}\right)$ will be rejected. This indicates that the data is stationary, and there is no existence of unit root problem. However, if the value of t-statistic is lower than the critical value, the null hypothesis $\left(\mathrm{H}_{0}\right)$ will not be rejected. This means the data is not stationary and there is existence of the unit root problem and that the series are not stable overtime.

\section{Johansen Cointegration Test}

The Johansen Cointegration Test is used to examine the correlation among variables over the long-term. The variables might be moved together correlated or uncorrelated. The eventuality of the cointegration test is to determine if two or more integrated (non-stationary) series can be combined to create (up to N-1) stationary series (Seiler, 2004 and Johansen \& Juselius, 1990). The Johansen Cointegration Tes will allow for both the trace and max-eigenvalue tests to be conducted. The Trace test is to examine the null hypothesis of number of cointegrating vectors which is less than or equal to $r$. The Maximum Eigenvalue test is to examine the alternative hypothesis of number of cointegration vectors which is larger than $r$. In the study, cointegration test is used to examine the long-term relationship between the gold price and the currencies exchange.

\section{Granger Causality Test with Vector Error Correction Model (VECM)}

The Vector Error Correction Model (VECM) Granger Causality Test is a statistical test to determine short-term relationship between the dependent variables and independent variables Granger (1969). The VECM Granger Causality Test is applied in the study to measure the causality and short-term relationship between the gold price and the currencies.

\section{Ordinary Least Square (OLS) Method}

Ordinary Least Square (OLS) is a method used to estimate the unknown parameter in linear regression model. The OLS method applied in this study is to determine whether there is positive or negative relationship between dependent variable (gold price) and independent variables (ASEAN currencies exchange rates include MYR/USD, SGD/USD and THB/USD). 


\section{FINDINGS}

\section{Augmented Dickey-Fuller (ADF) Unit Root Test results}

Table 1: Augmented Dickey-Fuller (ADF) Unit Root Test

\begin{tabular}{lcccc}
\hline & \multicolumn{2}{c}{ Level } & \multicolumn{2}{c}{ 1st Difference } \\
\hline Variables & Intercept & $\begin{array}{c}\text { Trend and } \\
\text { Intercept }\end{array}$ & Intercept & $\begin{array}{c}\text { Trend and } \\
\text { Intercept }\end{array}$ \\
\cline { 2 - 5 } LGGP & $1.494880(0)$ & $-0.114515(0)$ & $-17.16362(0)^{* *}$ & $-14.42710(1)^{* *}$ \\
MYRUSD & $-1.582051(1)$ & $-1.624928(1)$ & $-16.07883(0)^{* *}$ & $-16.08825(0)^{* *}$ \\
SGDUSD & $-0.803481(1)$ & $-1.732909(1)$ & $-12.69864(1)^{* *}$ & $-12.68663(1)^{* *}$ \\
THBUSD & $-1.900703(1)$ & $-1.894514(1)$ & $-14.75662(0)^{* *}$ & $-14.77374(0)^{* *}$ \\
\hline
\end{tabular}

Notes: Asterisks (**) indicates statistically significant 5 percent level. Figures in parentheses are the lag lengths. The ADF test examines the null hypothesis of a unit root against the stationary alternative.

The unit root test is run to test the stationary of time series data. If the value of t-statistic is greater than the critical value, the null hypothesis $\left(\mathrm{H}_{0}\right)$ will be rejected. This indicates that the data is stationary and that there is no existence of unit root problem. However, if the value of $t-$ statistic is lower than the critical value, $\mathrm{H}_{0}$ will not be rejected which that means the data is not stationary and there is unit root problem exist.

Based on Table 1, the result shows that all of the variables are not stationary in level stage because the value of t-statistic is lower than critical value of 95\% confidence level. Thus, the null hypothesis $\left(\mathrm{H}_{0}\right)$ will not be rejected because unit root problem exists. Nevertheless, the variables turned out to be stationary (significant) at 5 percent level of significant at the first difference because the t-statistic value is greater than critical value. Therefore, $H_{0}$ is rejected because unit root does not exist.

Based on the ADF unit root results, all the variables are stationary at $1^{\text {st }}$ difference. Thus, all variables are integrated of order I(1). This allows us to proceed to Johansen Cointegration Test.

\section{Johansen Cointegration Test results}

Table 2: Johansen and Juselius Cointegration Test

\begin{tabular}{|c|c|c|c|c|c|}
\hline \multirow[b]{3}{*}{ Null } & \multirow{4}{*}{ Alternative } & \multicolumn{2}{|l|}{$\mathrm{k}=2$} & \multicolumn{2}{|c|}{$\mathrm{r}=1$} \\
\hline & & Trace & & $\Lambda \max$ & \\
\hline & & Unadjusted & $95 \%$ C.V. & Unadjusted & $95 \%$ C.V \\
\hline $\mathrm{r}=0$ & & $76.85127 * *$ & 63.87610 & $39.97920 * *$ & 32.11832 \\
\hline $\mathrm{r} \leq 1$ & $r=2$ & 36.87206 & 42.91525 & 21.72778 & 25.82321 \\
\hline$r \leq 2$ & $r=3$ & 15.14429 & 25.87211 & 12.65251 & 19.38704 \\
\hline$r \leq 3$ & $r=4$ & 2.491778 & 12.51798 & 2.491778 & 12.51798 \\
\hline
\end{tabular}

Notes: $k$ is the lag length and $r$ is the co-integrating vector and $r$ is the number of co-integrating vectors that are significant under both tests. Asterisks (**) denotes significant at 5 percent significant level. 
The Johansen Cointegration Test is applied to examine the long-term relationship between the dependent variable (LGGP) and the independent variables (MYRUSD, SGDUSD and THBUSD). The maximum lags that have been chosen in cointegration test are lag $2(\mathrm{k}=2)$ with the results of one cointegrating vector $(\mathrm{r}=1)$ at $5 \%$ of significance level. With too many lagged values, for any additional lags which are not significant, it will reduce the likelihood that all the lagged values when taken as a group will be significant. (Seiler, 2004)

Based on Table 2, the result shows that there is an existence of long-term equilibrium relationship between the gold price and the exchange rate of ASEAN currencies against U.S. dollar (MYR/USD, SGD/USD and THB/USD). The trace test shows the computed value of 76.85127 , which is greater than critical value of 63.87610 . The maximum eigenvalue test also shows the computed value of 39.97920 , which is greater than critical value of 32.11832 . Hence both tests have rejected null hypothesis of no cointegration relation $(\mathrm{r}=0)$ at 5 percent of significant level. In addition, the result also indicates the existence of one cointegrating $\operatorname{vector}(\mathrm{r}=1)$ in the cointegration test.

The null hypothesis of at least one cointegration relation $(\mathrm{r} \leq 1)$, null hypothesis of at least two cointegration relation $(r \leq 2)$, and null hypothesis of at least three cointegration relation $(r \leq 3)$ for both trace test and maximum eigenvalue test have failed to reject the null hypothesis at 5 percent significant level.

Therefore, the results indicated that there is long-term equilibrium relationship between gold price and exchange rate of ASEAN currencies against U.S. dollar (MYR/USD, SGD/USD and THB/USD) in which the result contains one cointegrating vector. In other word, it means that both dependent variable and independent variables are co-integrated and has long-term relationship exist between dependent variable and independent variables.

Granger Causality Test with Vector Error Correction Model (VECM) result

Table 3: Granger Causality Test with VECM result

\begin{tabular}{lcccccc}
\hline $\begin{array}{l}\text { Dependent } \\
\text { Variables }\end{array}$ & \multicolumn{5}{c}{$\begin{array}{c}\mathrm{x}^{2} \text {-statistics } \\
(\mathrm{p} \text {-value })\end{array}$} \\
\hline \multirow{3}{*}{$\Delta$ LGGP } & $\Delta$ LGGP & $\Delta$ MYRUSD & $\Delta$ SGDUSD & $\Delta$ THBUSD & Coefficient & T-ratio \\
\cline { 2 - 7 } & - & 1.299201 & 1.683461 & 2.783724 & -0.03389 & {$[-3.47142]^{* *}$} \\
$\Delta$ MYRUSD & - & $(0.5223)$ & $(0.4310)$ & $(0.2486)$ & & \\
& 3.265404 & - & 1.387151 & 1.69641 & 0.024019 & {$[1.43083]$} \\
$\Delta$ SGDUSD & 2.045361 & 2.363045 & - & 4.419746 & 0.010688 & [1.96112] \\
& $(0.1954)$ & - & $(0.4998)$ & $(0.4282)$ & & \\
$\Delta$ THBUSD & 4.498546 & $(0.3068)$ & - & $(0.1097)$ & & ECT \\
& $(0.1055)$ & $(0.1045)$ & $(0.6586)$ & - & & \\
\hline
\end{tabular}

Notes: " $\Delta$ " is the first different operator. Asterisk (**) indicates statistically significant at 5 percent level. 
According to Table 3, the Granger Causality Test with VECM result indicates that there is no short-term relationship between the gold price and exchange rate of ASEAN currencies against U.S. dollar (MYR/USD, SGD/USD and THB/USD). It shows that the p-value (probability) of all variables is larger than 5 percent of significant level.

From the result, it shows that granger causality did not occur between gold priceMYR/USD and MYR/USD-gold price, similarly, gold price-SGD/USD and SGD/USD-gold price, and gold price-THB/USD and THB/USD-gold price.

This indicates that there is no short-term relationship exists among the gold price and exchange rates of ASEAN currencies against U.S. dollar (MYR/USD, SGD/USD and THB/USD). Therefore, the relationship between gold price and ASEAN currencies exchange rates (MYR/USD, SGD/USD, and THB/USD) can only be seen in the long-term period.

\section{Ordinary Least Square (OLS) Method result}

Table 4 shows that the probability of independent variables is 0.0000 , which is lower than the significant level of 5 percent. This means that the independent variables are significant in the model. Besides, it also shows that there is a positive relationship between gold price and MYR/USD exchange rate. However, gold price has inverse relationship with both of the $\mathrm{SGD} / \mathrm{USD}$ and THB/USD exchange rates. The equation that demonstrates the relationship between the gold price and ASEAN currencies exchange rates is as below:

$$
\log G P=6.62+0.77 M Y R U S D-0.45 S G D U S D-0.07 T H B U S D
$$

Table 4: Ordinary Least Square (OLS) Method

\begin{tabular}{lcccc}
\hline Variables & Coefficient & Std. Error & t-statistic & Prob. \\
\hline (Log Gold Price) & & & & \\
MYRUSD & 0.7761 & 0.1082 & 7.1728 & $0.0000^{* *}$ \\
SGDUSD & -0.4506 & 0.0701 & -6.4255 & $0.0000^{* *}$ \\
THBUSD & -0.0695 & 0.0084 & -8.2325 & $0.0000^{* *}$ \\
C & 6.6213 & 0.1974 & 33.5489 & $0.0000^{* *}$ \\
Statistics & & & \\
R-squared & 0.3066 & & & \\
Adjusted R-squared & 0.3008 & & & \\
F-Statistics & 52.4694 & & \\
Prob. (F-statistics) & 0.0000 & & \\
\hline Asterisk (**) indicates statistically significant at 5 percent level. & &
\end{tabular}

Based on the equation above, it indicates that $1 \%$ increase in MYR/USD exchange rate will lead to $0.77 \%$ increase in the gold price. Whereas, the increase of $1 \%$ in SGD/USD exchange rate will cause $0.45 \%$ decrease in the gold price. Moreover, the $1 \%$ increase in THB/USD exchange rate will lead to $0.07 \%$ decrease in the gold price.

In this study, Augmented Dickey-Fuller (ADF) unit root test has been used to examine whether the variables are stationary or not. The result has proved that all variables are stationary at first difference. 
The Johansen Cointegration test shows that there is long-term relationship between gold price and exchange rate of ASEAN currencies against U.S. dollar (MYR/USD, SGD/USD and THB/USD). This is consistent with the study by Wang, Wang and Huang (2010) which also shows that with the exception of United States itself, there is a long-term relationship among gold price and exchange rates of U.S. against other currencies such as Germany, Japan, Taiwan and China.

As for the result of Granger Causality test in VECM, it illustrates that there is no shortterm relationship between the gold price and exchange rates of ASEAN currencies against U.S. dollar. The empirical research is consistent with the study by Güneş et al (2009) which seems to show that there is no causality and short-term relationship between gold price and $€ / \$$ exchange rate and between gold price and interest rate. This seems to sugget that the relationship between gold price and exchange rate can only be seen in long-term not in short term period.

The result of Ordinary Least Square Method also show that gold price has positive relationship with Malaysia Ringgit (MYR/USD) but negative relationship with Singapore dollar (SGD/USD) and Thai Baht (THB/USD).

The result of the study provide important to investors. In determining the positive or negative relationship between gold price and exchange rate, the information is important for the investors, as it provides them with the alternative form of investment. For example, the negative relationship of gold price and SGD/USD exchange rate allows the investors to switch their investment to gold when the SGD/USD exchange rates weaken. This would allow the investors to take early action to prevent the potential risk of investment loss they may encounter in their investment. By being able gauge the correlation and changes among gold price and exchange rates, investors may be able to take any positive action, in order to cushion against any potential risks, and reduce their investment portfolio risk exposure.

\section{CONCLUSION}

This study examines the relationship between gold price and the exchange rate of ASEAN currencies which include Malaysia Ringgit, Singapore dollar and Thai Baht against U.S. dollar. The data that are utilized in the study include monthly data of gold price and exchange rate of MYR/USD, SGD/USD and THB/USD from the period of January 1981 to December 2010. The test implemented in the study include Augmented Dickey-Fuller (ADF) unit root test, Johansen

Cointegration Test, Granger Causality test with Vector Error Correction Model (VECM) and Ordinary Least Square (OLS) Method.

The ADF unit root test is applied to test the stationary of all variables. The result shows that all variables are stationary at first difference. The significant result of Johansen Cointegration Test indicates that a long-term relationship exists between gold price and exchange rate of MYR/USD, SGD/USD and THB/USD. However, the Granger Causality Test with VECM results, show that there is no short-term relationship between gold price and MYR/USD, SGD/USD and THB/USD exchange rate. The OLS method nevertheless, indicates that the gold price has positive relationship with MYR/USD exchange rate but shows inverse relationship with SGD/USD and THB/ USD exchange rates. The study is quite consistent with the graphic presentation of gold price over times by Morris, (2008), the gold price movement seems to stable at the onset of 1979 till the beginning of 2000s. Although the gold price has dropped in the last few years, it has fallen slightly which is incidentally coincidental with the end of the Bretton Woods System and Gold Standard. 


\section{REFERENCES}

Azar, S.A. (2015). The relation of the US dollar with oil prices, gold prices and the US stock market. Research in World Economy, Vol.6(1), 159-171

Baur, D. G. \& Lucey, B. M. (2010). Is gold a hedge or a safe haven? An analysis of stocks, bonds and gold. The Financial Review, Eastern Finance Association, Vol.45(2), pp. 217-229.

Beckmann, J., Czudaj, R. and Pilbeam,K. (2015). Causality and volatility patterns between gold prices and exchange rates. The North American Journal of Economics and Finance, 34, 292-300.

Blose, L. E. (2005). How changes in expected inflation affect the gold prices. Seidman College of Business, Grand Valley State University, Michigan Working Paper Series- Document No.005-05.

Broz, J.L. and Frieden, J.A. (2006). 'The political economy of exchange rate', in Weingast, B.(Ed), Hard Book of Political Science. Oxford, NY: University Press.

Capie, F., Mills, T. C. \& Wood, G. (2005). Gold as a hedge against the dollar. Journal of International Financial Markets, Institutions and Money, Vol.15(4), pp. 343-352.

Dickey, D.A. \& Fuller, W.A. (1981). Likelihood ratio statistics for autoregressive time series with a unit root. Econometrica, Vol.49(4), pp 1057-1077.

Figuerola-Ferretti, I. \& Gonzalo, J. (2010). Price discovery and hedging properties of gold and silver markets. European Financial Association Annual Conference, School of Business, Aarhus University, Aarhus, Denmark. NGS/2010Aarhus/EFMA2010_0378_fullpaper.pdf

Faugere, C. and Van Erlach, J. (2005). The price of gold: A Global Required Yield Theory. The Journal of Investing, Vol.14 (1), pp 99-111.

Ghazali, M.F., Lean, H.H., Bahari, Z. (2015). Is gold a good hedge against inflation? Empirical evidene in Malaysia. Kajian Malaysia, 33(1), 69-84

Ghosh, D., Levin, E.J., Macmillan, P. \& Wright, R.E. (2002). Gold as an inflation hedge? Studies in Economics and Finance, Vol.22(1), pp 1-25.

Granger, C.W.J. (1969). Investigating causal relations by econometric models and cross-spectral methods. Econometrica Vol.37(3), 424-438.

Güneş, H., Güler, F., Özkalay, M. A. \& Laaganjav, B. (2009). Effect of oil price, interest rate and dollar price of Euro on gold price. Empirical Studies In Social Sciences, $6^{\text {th }}$ International Student Conference, Izmir University of Economics, Izmir Turke.

Han, A., Xu, S. \& Wang, S. (2008). Australian Dollars exchange rate and gold prices: An Interval Method Analysis. 7th International Symposium on Operations Research and Its Applications,Lijiang, China, pp.46-52,

Jain, A., and Ghosh, S. (2013). Dynamics of gold prices, exchange rate and precious metal prices in India. Resources Policy, 38(1), 88-93

Johansen, S. \& Juselius, K. (1990). Maximum likelihood estimation and inference on cointegration-With applications to the demand for money. Journal Oxford Bulletin of Economics \& Statistics, Vol.52, Iss.2, pp 169-210.

Joy, M.(2011). Gold and the US dollar: Hedge or heaven? Finance Research Letters, 8, 120-131

Malliaris, A.G., and Malliaris, M. (2013). Are oil, gold and euro inter-related? Time series and neural network analysis. Review of Quantitative Finance and Accounting, 40, 1-14.

Mansor, I.H. (2011). Financial market risk and gold investment in an emerging market: The case of Malaysia. Romanian Journal of Economic Forecasting, 14, 79-89.

Marzo, M. \& Zagaglia, P. (2010). Gold and the U.S. Dollar: Tales from the turmoil. Working Paper No. 08-10, Rimini Centre for Economic Analysis, Rimini.

Morris.J.H. (2008). The seeds for this CREDIT CRUNCH were sewn during Reagan Thatcher times. Capitalism would become Corporatism. Retrieved September 11, 2010, from 
http://morris108.wordpress.com/2008/09/09/the-seeds-for-this-credit- crunch-were-sewnduring-reagan-thatcher-times-capitalism-would-become-corporatism/

Partalidou, X., Kiohos, A. Giannarakis, G., and Sariannidis, N. (2016). The impact of gold, bond, currency, metals and oil markets on the USA stock markets. International Journal of Energy Economics and Policy, 2016, (6)(1), 76-81

Pukthuanthong, K., and Roll, R. (2011). Gold and the dollar (and the euro, pound, and yen). Journal of Banking and Finance, 35(8), 2070-2083.

Seiler, M.J. (2004). Performing Financial Studies. A Methodology Cookbooks. New Jersey: Prentice Hall.

Sjaastad, L. A. (2008). The price of gold and the exchange rates: Once again. Journal of International Money and Finance, Vol.33(2), pp. 118-124.

Wang, M. L., Wang, C. P. \& Huang, T. Y. (2010). Relationships among oil price, gold price, exchange rate and international stock markets. International Research Journal of Finance and Economic, Issue 47, pp.80-89, 17.

Zagaglia, P. and Marzo, M. (2013). Gold and the Us dollar. Quantitative Finance, 13(4), 571-582.

Corresponding Author: Michael Tinggi can be contacted at tmichael@unimas.my 